\title{
The gift in A\&E: re-framing the medical case presentation through Mauss
}

Case presentations have totemic significance in medical sociology, in which they are analysed as emblematic of medical professional culture. This article makes a case for conceptualising these exchanges in terms of Mauss' account of gift giving, which theorises sociality in terms of obligations voluntarily incurred and reciprocated and the performative recognition of hierarchy. This contrasts with two alternatives in existing literature: the case presentation as an instance of pedagogically-oriented supervision and legitimate peripheral participation; and as representative of professional discourse more generally. We make our case for reframing the case presentation in relation to video and audio data generated within a study of an Accident and Emergency department in the UK. We conclude that Mauss' concept of community allows us to see discursive phenomena that have been overlooked, and to theorise the work of junior doctors in terms of collegiality in a hierarchically-organised profession, by contrast to a defective version of the work of their superiors or the manifestation of singular professional discourse.

Keywords: hospital ethnography, case presentation, discourse analysis, ritual, socialization, institutional order, emergency department

Mauss' 1924 book The gift: forms and functions of exchange in archaic societies might not seem an obvious place to start from in making sense of a contemporary accident and emergency (A\&E) hospital department. How could 
its argument about the potlatch or the kula exchange have relevance for studying the unmystical character of contemporary medicine?

This article is unfortunately not about dance ceremonies in UK hospitals. It is concerned with making sense of certain discursive features of the case presentation: about what is going on when junior doctors present cases to their seniors who then give back advice on how the case should be pursued. In medical sociology, this exchange has the status of a kind of 'total social fact' (Mauss, 1924), capturing something essential about how the institution holds together. For instance, Hunter (1991, p.51) describes the case presentation as the manifestation of the basic unit of thought and discourse in medical culture: "As a fundamental ritual of academic medicine, the narrative act of case presentation is at the center of medical education and, indeed, at the center of all medical communication about patients".

Linguistic analyses of the case presentation have identified the main devices constitutive of this totemic event. However, attention has focused on the discursive structure of the event itself rather than its role in the life and work of a community: the 'movement of the totality', its circulation, 'the fleeting moment' in motion as the exchange is initiated and then forces activity onwards (Mauss 1924, p.103).

This is for two main reasons. First, the reliance on models of sociality that focus on relations between individuals or positions in a professional community, rather than on the differentiation and coordination of activities. Discursive 
interactions constituting the case presentation are then interpreted as indicative of states of knowledge, rather than exchanges within ongoing, purposive work activities (we expand on this in the next section). Second, the difficulties of following temporally variable but often extended cases in bustling and noisy clinical workplaces. Mauss' concept of the gift is helpful in analytically re-framing the case presentation, as a ritual whose linguistic features pertain to its place and purpose in interactional exchanges constitutive of a case more widely. It has also helped us make sense of video and audio data collected in a pilot study intended to investigate how work activities in a busy A\&E department might be researched. The concept has two linked functions, then, in this article: to critique the analytic construction of the case presentation in existing literature; and to organize an analysis of data generated using innovative methods. We conclude by drawing out the relevance of this re-framing of the case presentation for interpreting its discursive characteristics and making sense of how clinicians work collaboratively and hierarchically.

\section{Researching the case presentation to educate novices}

Whilst the clinical literature on the case presentation consists primarily of guidelines written by 'experts' (Chan, 2015), empirical analyses of case presentations can be divided into two traditions according to how they construct their object analytically.

The first tradition, epitomized by the work of Lingard and associated researchers (Lingard et al, 2003 and 2003a; Lingard and Haber, 1999; Kennedy et al, 2009; Spafford et al, 2006; Haber and Lingard, 2001; Schryer and Spoel, 2005) is 
primarily concerned with ensuring that novices can be effectively supported in becoming experts. Lingard's research team compares the rhetorical strategies deployed by senior physicians and novices (third year medical students), explaining these in terms of history, identity and position in the community. For instance, novice physicians are seen to deploy strategies illustrating 'thinking like a student' (Lingard et al, 2003a). This is because they are concerned with getting good marks, rather than working collegially.

Lingard's analysis draws on Lave and Wenger's (1991) anthropological account of apprenticeship. Consequently, the case presentation is figured as a dyadic encounter in which a supervisor exercises control over the work of an apprentice, with the latter endeavouring to become like the supervisor, his/her speech treated analytically as a form of 'ventriloquising' (Lingard et al, 2003a). As Lingard states: "by participating in this discursive process, clinical trainees learn how to talk and think medically" (Lingard and Haber, 1999, p.124, our emphasis). This obscures from view trainees' contribution to the division of labour. Their speech is heard as deferral, rather than differentiation. Analytic concern focuses on how novices do not speak and work like experts yet, rather than on how they speak to carry out their own work duties now; how they 'think and talk medically' already, as members of a professional hierarchy. Lingard's work is based on observations of third year medical students, not qualified, working doctors (many of whom are also 'trainees', by virtue of the hierarchical organization of the medical profession). But this is not treated as analytically relevant for analyzing the case presentation: claims are related to the practices of 'students', 'novices' and 'trainees' interchangeably. 
Because the case presentation is figured as an instance of 'modelling' (Pomerantz et al, 1995), its purpose in work is overlooked. For instance, Erickson (1999, p.113), developing Lingard's argument that the case presentation is an instance constituted by 'the appropriation of voice' by trainees, notes that the problem with such trainees is that "what they have learned in previous years as medical students is how to present a case formulaically to a teacher rather than how to discuss a case with a fellow physician to a purpose" - but this purpose is itself never described. What is it? The purpose of supervision is accounted for, but the case presentation is never analysed in terms of its purpose for working. It consequently appears an instance of 'communication', rather than procedures and roles, an analytic move which Strong (1979/2001, p. 5) criticized for neglecting diagnosis as 'a social occasion', structured within an organizational framework. This neglect makes professional action appear as largely a cognitive affair: the exercise of independent thought and speech, as modelled by 'expertteachers' (Pomerantz, 2003). Goodwin (2014) notes the popularity of this figuring of the medical practitioner, but makes the point that medical practice is better represented as an ongoing flow to which multiple voices contribute, incurring dependencies on each other as contributions are interlaced; diagnoses and decision-making are distributed, not independent, events. This distribution 'teamwork', in a more familiar register - is not visible when the case presentation is analytically isolated from the work-oriented exchanges of which it is one part.

\section{Researching the case presentation to describe medical socialization}

Studying how medical work is done is the focus of the second tradition for 
researching the case presentation. We identify the main reference points as Anspach (1988), Atkinson $(1994,1995,1999,2004)$ and Hunter (1991). Anspach's is one of the first studies to pay close attention to the language of the case presentation. Like Lingard, Anspach sees in this the manifestation of an opposition, but not between novice and expert, rather between "deeper assumptions [that are...] tacit and taken for granted", notably the low priority given to 'social issues', and "the explicit tenets of medical education" which emphasise their importance (p.372). In particular, Anspach interprets the use of the passive voice in case presentations (e.g. 'the CT scan shows...' rather than 'I interpret the CT scan to show that...') as a socialisation strategy by which senior physicians impose a de-socialised view of medicine on juniors.

In adopting a more ethnomethodological stance, Atkinson withholds from Ansprach's demystifying critique, and focuses instead on the coding of credibility: how physicians display judgment about the work and claims of others, and in so doing, affiliate themselves - or not - with colleagues and patients. This is treated as constitutive of the poetics of medical practice, rather than reflective of individual states of knowledge. What Atkinson hears in a case presentation, then, is not so much how individuals claim credibility; rather, he treats the marking of credibility or value in the circulation of accounts as what constitutes clinical practice.

In this respect, Atkinson develops Hunter's (1991) argument that clinical work is performed by means of the exchange of narratives: patients tell stories to doctors to gain admission, and doctors narrativise patients in order to be able to 
work with colleagues. Hunter's account traces how clinical practice consists of circulating presentations and re-presentations of narratives. Her analysis makes salient what Anspach and Atkinson exclude from their studies: a contextualization of the case presentation within a sequence of activities. In Anspach's study, this is because the case presentation is treated as metonymic of medical culture, figured as set of values rather than a sequence of interactions. In Atkinson's study (1999), this is because of the choice of empirical setting - a hematology unit - in which the case presentation operates as an occasion on which authority and responsibility are established, without necessarily informing subsequent activities. Hence the appropriateness of Atkinson's method of data collection, which involves putting a recorder on a table around which the hematologists sit. This depiction of the case presentation contrasts with Hunter's image of the circulation of narratives round the hospital. Yet whilst Hunter treats the case presentation as a step in an extended movement, she does not attend to this in detail, including how narratives change as they circulate.

\section{Mauss' Gift}

In the first tradition for analyzing the case presentation, then, accounts identify how novices learn to speak professionally, but not how speech sustains professional activity. In the second tradition, an account of a generic discursive event is isolated from the sequence of other professional activities that inform its meaning. In anthropological terms, the first tradition focuses on community entry but not maintenance; and the second focuses on maintenance, but not outwith the metonymic ritual itself. 
Mauss' account of gift-giving makes salient aspects of the case presentation which seem to be neglected. These include the autonomy of those making the case presentation manifest in activities preceeding and following it and elements of the discursive dynamics within it; as well as the collegial obligations enforced through the case presentation, established in relation to work activities, notably patient referral. To expand on this, we will provide an overview of Mauss' concept of the gift and how it accounts for autonomy, obligation, and their conjunction through the circulation of goods.

\section{Gift-giving as a ritual for establishing autonomy and reciprocity in social life} Mauss' concept of the gift asserts that a hierarchically-organised social order is maintained through exchange and reciprocity, which enforce inter-dependence. What holds a community together, then, is not the imposition of control, or the enforcement of legal requirements, but 'a system of reciprocity' (Douglas, 2002) emerging from the circulation of wealth. 'Wealth' takes many forms, from valuable objects to politeness markers, and in recent interpretations of Mauss' book, organizational knowledge (Konstantinou and Fincham, 2010). In Karsenti's (1994, p.52) reading, wealth is whatever assumes "social significance".

Mauss' vision of social order counters those which rely primarily on domination as an explanatory principle, be this benevolent (as in Lave and Wenger's model) or oppressive (as in Anspach's concept of socialization). A gift is given voluntarily. Freedom to give is what constitutes its meaning. Mauss does not however indulge in a Rousseauesque spirit of generosity. Exchanging gifts is a social obligation, performed under the appearance of autonomy. Mauss' concept 
is thus a way of understanding the emergence of legitimate authority versus control, and inter-dependence versus independence/mastery. When compared to Lave and Wenger's model of community, it makes visible how members are not central to community life by virtue of expert practice and the power/authority this grants to control others; rather, authority is exercised by reciprocating services rendered. Mauss' vision of community suggests, for instance, that senior doctors might depend on trainees to be able to work.

Mauss' concept treats hierarchically-structured exchanges as performatively reinscribing formal positions rather than merely reflecting them (as in Lave and Wenger's analytic model). This means that identity and status are always at stake, rather than securely given. Giving a gift exercises force; it obliges a return. To present a gift is to manifest superiority. To accept without returning or returning less is to subordinate oneself. The exchange of gifts is thus a conflict over prestige. Also, because a gift is a symbol, pertaining to the network of relationships within which the symbol assumes meaning, gift-giving frames dyadic encounters analytically within a plurality of relations constituting the community.

Analysing the case presentation as an occasion for the presentation and return of gifts makes visible phenomena that are not widely reported on. The voluntary framing of a case presentation is made salient: the way in which a case is offered, with prominent politeness markers, by a trainee to a senior physician, as a discursive object of value symbolic of work performed and the status of the presenter; the way in which acknowledgements, signatures, advice and 
endorsements are obligingly, unfailingly returned, with elaborate thanks, symbolizing the honour of the senior physician; and the subsequent, selective circulation of what is returned to patients and other physicians, a force which makes the case evolve and medical work happen.

Treating the case presentation as a ritual of gift-giving also makes sense of the claim various parties have over what is presented and received: how a case remains the trainee's as, and after, it is presented; how seniors accept a presentation only when they are able to return something of even greater value, and how this makes hierarchy perceptible in interactional practice. Our claims here have analytic parallels with Strong's (1979/2001) representation of medical work as ceremonial. Strong pointed to how authority relationships in patient consultations require constant dramatisation for their successful enactment. We argue that the ceremony of the case presentations dramatizes distributed responsibility, transforms investigations into a 'management plan', and thereby gets work done.

One obvious objection to treating the case presentation as a gift-giving ritual is that it is a formal requirement. However, in our study, the case presentation was not treated as such. It was discursively marked as voluntary in its status, a case of "double-checking", albeit sometimes required to obtain a signature. Furthermore, Mauss emphasizes that the concept of the gift is a way of studying how rights are lived in practice. This makes sense of how the case presentation functions normatively: how it works to oblige, but not require, responses; how reciprocity, rather than obedience, is effected; and how references to formal 
duties are largely absent, and thus cause disturbance - anger, the expression of humiliation, of a breach of etiquette - when they do appear.

Recruiting Mauss concept of the gift is not intended to provide an alternative, exhaustive account of the case presentation. It allows us rather to see discursive phenomena that have been overlooked. In terms of analysis, it means that we move between the case presentation itself and contextualizing data. This implies less detailed analysis of the case presentation itself, compared to existing discourse analyses, but more emphasis on associated activities. Our approach here is made possible by the innovative design of the study.

\section{The research design}

Our study started as a collaboration with an A\&E consultant who was interested in finding out why junior doctors (trainees in their second year of work) had difficulties making decisions. He evoked these difficulties in terms of juniors spending too much time - and thus the departmental budget - on tests which deferred rather than enabled decisions. This question led to a research design intended to find out how junior doctors did their work, rather than specifically the difficulties they faced, a move intended to study their involvement in decision-making rather than their 'novice' status. Our study was a pilot exercise, to establish how work practices in an A\&E department could be studied empirically, since this setting poses particular challenges (Stevenson et al, 2015).

Our research site was a hospital in south-east England. Research on A\&E sometimes called ED (emergency department) - highlights its gatekeeping 
function in relation to other health services (e.g. Buchbinder, 2017; Hilligloss, 2014; Hillman, 2013). Although A\&E is the most open hospital-based service, it has almost exclusive control over access to further hospital-based treatment. Its organizational function is to 'dispose' of patients by handing them over to other services (Stevenson et al, in press). Upon arrival in A\&E, patients are triaged, usually by a nurse (Hughes, 1988), and, in our setting, were then most commonly seen by a junior doctor, unless their condition was serious enough to warrant immediate attention from a consultant.

Following approval by an NHS ethics board, our research team undertook fieldwork in two-stages between October 2014 and March 2015. The first involved observations at various times of day and night. The second stage involved the use of a static video camera to record the initial consultation between a patient and a junior doctor, as well as use of a handheld camera to record subsequent interactions between the junior doctor and other clinicians. For each recorded patient case, the junior doctor also wore a lapel microphone. We gathered data on sixteen patient cases, a case here meaning the activities performed by a junior doctor in association with one patient. Those cases were done by eight junior doctors, with case presentations involving nine different consultants. Full verbatim transcripts were completed for all cases.

In this paper, we draw primarily on audio-visual records rather than field notes. The latter however inform our analysis, not least by making apparent what recordings did not capture. This includes how the deployment of recording equipment intervened in clinical working. Our perception of junior doctor's 
autonomy has been heightened by some consultants' reluctance to be filmed (to avoid 'tainting' research understood to be about junior doctors, and also sometimes because the hospital expected access to the data on request), as well as some consultants' interest in demonstrating supervision (for the perceived benefit of our research). However, we do not think our presence, and that of our equipment, seriously threatens the credibility of our argument. Audio-visual recording sometimes enhanced certain behaviours, but was made sense of in the light of such behaviours. For example, junior doctors sometimes referred to the recording equipment to influence colleagues' actions, which highlighted how collegial obligations could not simply be requested. Persuasive resources had to be mobilized, and our recording equipment added to these.

An unanticipated benefit of video recording is that the researcher and the junior doctor conversed regularly about what had been recorded, to enable the researcher 'catch-up' on what she had not witnessed directly (after the first research phase, the researcher did not observe consultations directly). These interactions make perceptible what we would otherwise have failed to see, including a junior doctor's interpretation of a case and how it should be handled. Because of this, we were able to see the work performed by junior doctors outwith the case presentation.

We have organized our analysis under two key aspects of Mauss' account of giftgiving: autonomy and return. We then examine an instance in which gift exchange fails, and the interactional difficulties this leads to. 


\section{The autonomy of the gift in $A \& E$}

As outlined above, the case presentation is often figured as a disciplinary moment, in which seniors exercise control and socialize juniors into the profession by requesting displays of competence. Without denying this, the research design allowed us to see how autonomy was exercised: junior doctors chose when to present the case, what to include in it and also what to omit. In two of our sixteen cases, they decided not to present a case at all. Junior doctors (JD) almost always instigated case presentations:

\section{Extract 1, Case 2:}

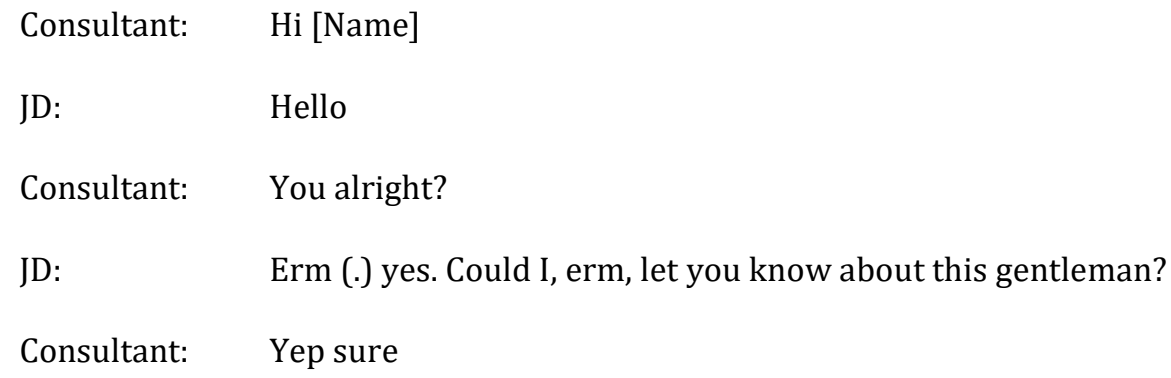

Extract 2, Case 9:

JD: $\quad$ Hi [Name] sorry are you in charge?

Consultant: $\quad$ Hi [Name]

JD: $\quad$ Or is it doctor [Name]?

Consultant: I'm in charge

JD: $\quad$ You are

Consultant: Go ahead

JD: $\quad$ Fantastic, may I discuss the patient with you please?

Consultant: Go ahead 
The opening request formulations signify the case presentation as a voluntary exercise: the use of modal verbs ('could', 'may'), the interrogative structures, the use of softeners ('please', 'sorry') and the hesitation devices frame the case presentation's initiation as a tentative offer, hedged with markers of deferential politeness. The phatic formulation of the consultant's greeting in Extract 1 ('You alright?') signifies his availability but leaves the junior doctor to determine the purpose of the interaction. Even when explicit reference is made to the formal division of labour (Extract 2: 'are you in charge?'), an offer requires consent before it begins ('may I discuss the patient with you please?' following the first 'go ahead', which is then repeated before the case presentation begins): a case presentation is not initiated in reference to duties, but as an offer - to 'let you know' or 'discuss'.

This interpretation is reinforced by exceptions to the rule: our data set includes only one instance of a consultant requesting a case presentation, as part of a board round. He offers lengthy justification (15 lines) for this:

Extract 3, Case 10:

Consultant: You alright, fellah?

JD: Yeah

Consultant: $\quad$ Are you in the middle of something or (.)?

JD: $\quad$ I was just requesting an x-ray

Consultant: What I'll do, just to save your time, I'll go through the ones who are unreferred, just to make sure we've got plans for all

[15 lines removed]

Consultant: $\quad$ OK, what have you got? 
The consultant acknowledges the work being carried out by the junior doctor autonomously, and frames the case presentation as an instance of what Kendrick and Drew (2016, p.9) theorise in terms of 'projectable trouble' in the recruitment of assistance: the request is presented as a subsidiary action to the junior doctor's own work ('are you in the middle of something'), and an unsolicited offer of help which altruistically preempts need ('to save your time'). The repetition of 'just' in the consultant's third turn minimizes both the obligation entailed in the demand as well as its disruptive effect. Note the lack of imperatives: the consultant acknowledges the norm of consultant approval prior to referral and the establishment of a 'plan', but this is marked as a collaborative enterprise expressing solidarity ('we've got plans) and voluntary assistance in the realization of the junior doctor's course of action, rather than control of his work.

Our point here is that in interactional terms, a case presentation is offered to a superior, not requested; and its deferential offer leads to a collegial return. Case presentations are thus initiated so as to enable consultants return a service. The case presentation then is not only an occasion on which junior doctor's credibility is at stake, as Lingard et al (2003) argue; so is the consultant's. This is significant, as case presentations have often been interpreted primarily in terms of how juniors try, and fail, "to make themselves look professionally competent" (Erickson, 1999, p.136). This leads to conclusions about their thinking like novices, and to the reading of the case presentation as a display of the junior's 
competence, with the senior's competence treated as given. We would argue that case presentations are structured to allow consultants also to display competence; to do the work of superiors in the hierarchy.

This becomes particularly visible when one compares what junior doctors say to patients and other clinicians, as well as to the researcher shadowing them, with what is said in the case presentation. The extract below is an exchange between the researcher and a junior doctor after an initial patient consultation:

\section{Extract 4, Case 9:}

JD: Do you want me to explain anything to you or not really?

Researcher: Yes, yeah, yeah

JD: What I've decided to do?

Researcher: Yes

JD: $\quad$ OK. So she's had a cough for eight days. And she's a little bit short of breath with it and her chest, to me, no wheeze, no creps [...] Yeah, but, erm, I'm not too worried but the fact that she's had it for a few days now and it's not going away, and she's brought up some blood, so I'm doing a chest x-ray for her

The junior doctor explains to the researcher what she has decided to do. Note the lack of the passive voice here, and reference to a decision she has already made ('what I've decided to do' then 'I'm doing a chest x-ray for her'); the junior doctor claims the decision as her own as well the course of treatment she has initiated. When she presents the case to the consultant, this state of affairs is evoked as follows: 
Extract 5, case 9:

JD: $\quad$ She's awaiting [x-ray

Consultant: $\quad$ So in summary] sixty-nine year old lady with eight days history of cough

The ordering of the $\mathrm{x}$-ray is here presented in the passive voice; it is a state the patient is in ('she's awaiting'), rather than a decision the junior doctor has made (as in extract 4). To paraphrase Anspach, the junior doctor denies her agency. The consultant does not respond to the junior's reference to an x-ray and the initiation of investigation it implies, but summarises the history and presenting symptoms - the overlap in speech, the initial 'so' and also the absence of any eye contact highlighting a transition as the consultant takes control over the interaction. He extends the summary over several more turns, asking questions and confirmations. He then states:

Extract 6, case 9:

Consultant: Ok so this lady needs a chest film [i.e. an x-ray] to look for a chest infection, JD: $\quad$ Mmm

Consultant: The majority of cases with evidence of blood mixed with the sputum or mixed with the phlegm is likely to be arising from the upper respiratory track

JD: $\quad$ Yeah

Consultant: And acutely in the context of infection doesn't require that much alarm JD: $\quad$ Yeah

The consultant states that the patient needs an x-ray, but makes no reference to the junior doctor's prior indication that the patient is awaiting this. He provides 
justification for why the investigation is warranted (as did the junior doctor in extract 4). The justification which accompanies the treatment plan might be read as a form of teaching ('the majority of cases....'), and modelling of 'thinking like an expert'. It appears only by virtue of the junior doctor withholding her justifications for having ordered an x-ray already.

The point we wish to make in relation to these last three extracts is that the junior doctor does not display credibility in the case presentation by identifying and justifying her 'decision' to do an x-ray (as she does to the researcher in extract 4), but rather by re-presenting the patient's history and symptoms in a rhetorical form which denies diagnostic or clinical interference. This allows the consultant to give back his treatment proposal and rationalization. It is in this regard that the junior doctor might be said to be practising professionalism: enabling the consultant to be 'in charge' and acting as his vassal at the bedside.

This interpretation affects how the use of the passive voice might be understood. Rather than a generalized denial of subjectivity characteristic of medical culture (as in Anspach), it might be read instead as a strategy to create discursive space for superiors to re-inscribe their position in the hierarchy.

Case 9 was one of six we coded as instances in which the consultant issues the same diagnostic and treatment proposal as ones which the junior doctor had already made, without either party identifying repetition or redundancy in the exchange (the other cases are coded, in order of decreasing frequency, as instances in which the consultant recommends additional tests, queries work 
done and re-directs aspects of it, there is no case presentation, and disagrees with proffered conclusions).

This puts into question the purpose of the case presentation. Both Saunders (2008) and Atkinson (1999) indicate that this is not straightforward. Atkinson concludes that it serves to establish 'proper responsibility' and shared understanding. Whilst the offer of a case to a consultant supports the argument about responsibility, we suggest that, in our setting, this is to some degree opposed to 'shared understanding', since 'understanding' is what the junior doctor withholds, leaving room for the consultant to provide his. In other words, responsibility is assumed in the return of understanding for the gift of the case presentation.

The gift-like status of what is returned is visible in the occasional deviation from the plan after the case presentation. Such deviations are in our eyes (and data) only and were not identified as such by junior doctors. The deviations consist of tests ordered by juniors doctors which are explicitly referred to as unnecessary by the consultant; the waiting for test results prior to referral, against the consultant's advice; and the provision of advice to patients which contradicts the consultant's recommendations. In each case, such deviations help enforce a referral, in the face of reluctant colleagues or patients. This corroborates Hilligloss' (2014) argument that ED doctors engage in additional testing to preemptively strike against resistance, although our study suggests that the burden of such work falls to junior doctors without consultants necessarily knowing about it. 
So far, the concept of the gift has enabled us to highlight two aspects of the case presentation. First, how gifts, in the form of accounts marked as voluntary, circulate in $A \& E$, increasing in value with respect to getting the work of $A \& E$ done. Second, how exchange inscribes hierarchy. Juniors do not give gifts which are superior in value to those returned by seniors.

\section{Enforcing obligation and reciprocity through gift return}

Fritsch $(2015$, p.8) argues that what obliges a gift to be given back concerns the effecting of assimilation and differentiation: "The obligation to reciprocate stems from the fact that in accepting the gift, the recipient assimilates that which will remain other even as it co-constitutes his subjectivity as well as (though in a different way) that of the donor". The closures of case presentations, often featuring extended exchanges of politeness markers, illustrates this dynamic:

\section{Extract 7, Case 15:}

Consultant: okay alright okay

JD: $\quad$ okay

Consultant: excellent

JD: $\quad$ thank you very much

Consultant: thank you well done

The consultant's 'excellent' passes judgement on the situation established jointly through the exchange. It is offered back to the junior doctor, to close an interaction which he initiated, and to display the completion of the interaction's institutional objective (Antaki et al, 2000). The consultant's final turn both marks 
reciprocity through repetition of 'thank you' but also re-enforces his evaluative position over the junior doctor: superiority is established through generosity.

The giving and giving back of thanks symbolizes the process by which the junior doctor brings a case to a consultant, who then gives it back in an altered form, the alteration consisting of the assimilation of what's been given and the creation of a 'joint' plan. The giving back re-establishes the junior doctor's autonomy: the patient and the case remain his or hers after the case presentation. This seems crucial to emphasise, since it contrasts with arguments in the educational literature that only senior physicians have/feel responsibility, and that autonomy is gradually granted to juniors in return for the display of competence (Wallenburg et al, 2013). We would argue that autonomy is generated on the basis of an obligation to abide by the spirit (if not always the letter, as discussed above) of what's been returned.

The obligation incurred during the case presentation does not extend to patients and clinical services. For instance, in referring or discharging patients, junior doctors usually made no reference to consultant advice (in talk, at least, but we had no access to electronic records). However, the way in which a junior doctor secured a referral or a discharge parallels the dynamics of the case presentation, with the junior doctor volunteering gifts in the form of diagnostic information. Our point here is that although a case presentation concluded with reference, for instance, to a referral, this did not have the status of an order: junior doctors could not order referrals, including in reference to their consultant. An invitation had to be accepted. Reciprocity, not instruction, was manifest. 
This can be illustrated in relation to Case 4, which featured an elderly lady who the junior doctor described to a nurse as "not safe on her legs". He stated the difficulty the case presented: "the only thing is that there's not really much story that I've got. What's her reason for admission?" The patient could not be discharged because she could not walk, but neither could she be admitted without a 'story' to oblige acceptance of a referral. In an endeavor to construct this story, he ordered various diagnostic procedures. The consultant ratified these: "just do what you need to do for the medics...if you feel you've got enough to make a convincing story". The consultant approved the plan to refer the patient to the general medical ward, but assigned responsibility for constructing 'a convincing story' back to the junior doctor. The junior doctor explained the situation to the researcher as follows: "we'll do the urine, and if she's got a urine infection, they [the medics] can't say no, essentially." This explanation is reminiscent of research on ED work (Nugus et al, 2009; Hilligloss, 2014) which identifies metaphors of 'selling' and 'giftwrapping' patients to secure admissions to inpatient services.

Case 4 highlights two aspects of our argument. First, the autonomy of the junior doctor: he was responsible for securing the referral. Second, reciprocity enforced through gift-giving emerged not only in relation to the case presentation but also other exchanges, including between clinical departments. This analysis develops Hunter's argument that medical care is achieved by means of narrative transactions, but whereas Hunter focuses on narrative as a mode of understanding, Case 4 suggests that it is also a matter of operational force: the 
junior doctor did not construct a narrative to understand the case but rather to oblige a return. This was in effect his job: to force others into graciously reciprocating motion

\section{Breaching etiquette}

Our construction of the $A \& E$ department as a site for the circulation of gifts highlights how collegial hierarchy - by contrast to control and instruction - is established. We also have many examples of ruptures in the expectations of giftgiving, consisting of extended interactional difficulties. In existing literature, these are explained in terms of 'novice performance', such as the presentation of "clinically accurate but rhetorically irrelevant patient information" (Lingard et al, 1999, p.24). This argument however does not attend to the etiquette relevant to interactions between juniors and seniors, and notably the deference due from one to the other. Our data set suggests that when junior doctors give diagnoses without first having been given back this responsibility by consultants in return for patient information, interactional difficulties can ensue.

Case 6 illustrates this. It features a junior doctor who, in the initial consultation with the patient, offers a diagnosis of a potential stroke, stating that he'll order a CT scan and refer her to the stroke team. The junior doctor then approaches the consultant to obtain the signature for a CT scan:

Extract 8, case 6:

JD: $\quad$ Dr [Name] I've got an elderly lady who

Consultant: Yes 
JD:

I'm afraid might have had a stroke yesterday (.)

Consultant: Tell me about her focal neurological deficit

JD:

So she's a sixty-seven years lady...

The junior doctor does not request permission to start the case presentation. He gives a diagnosis without presenting the patient's history, present complaint or the result of investigations. This breaches the normal order of exposition, which offers a listener grounds from which to return questions and recommendations. In asking about the focal neurological deficit, the consultant requests justifications for the diagnosis. The junior doctor seems to interpret this question as a call to order, since he starts giving a history in the traditional format, starting with age and gender. Then, 48 lines later:

Extract 9, case 6:

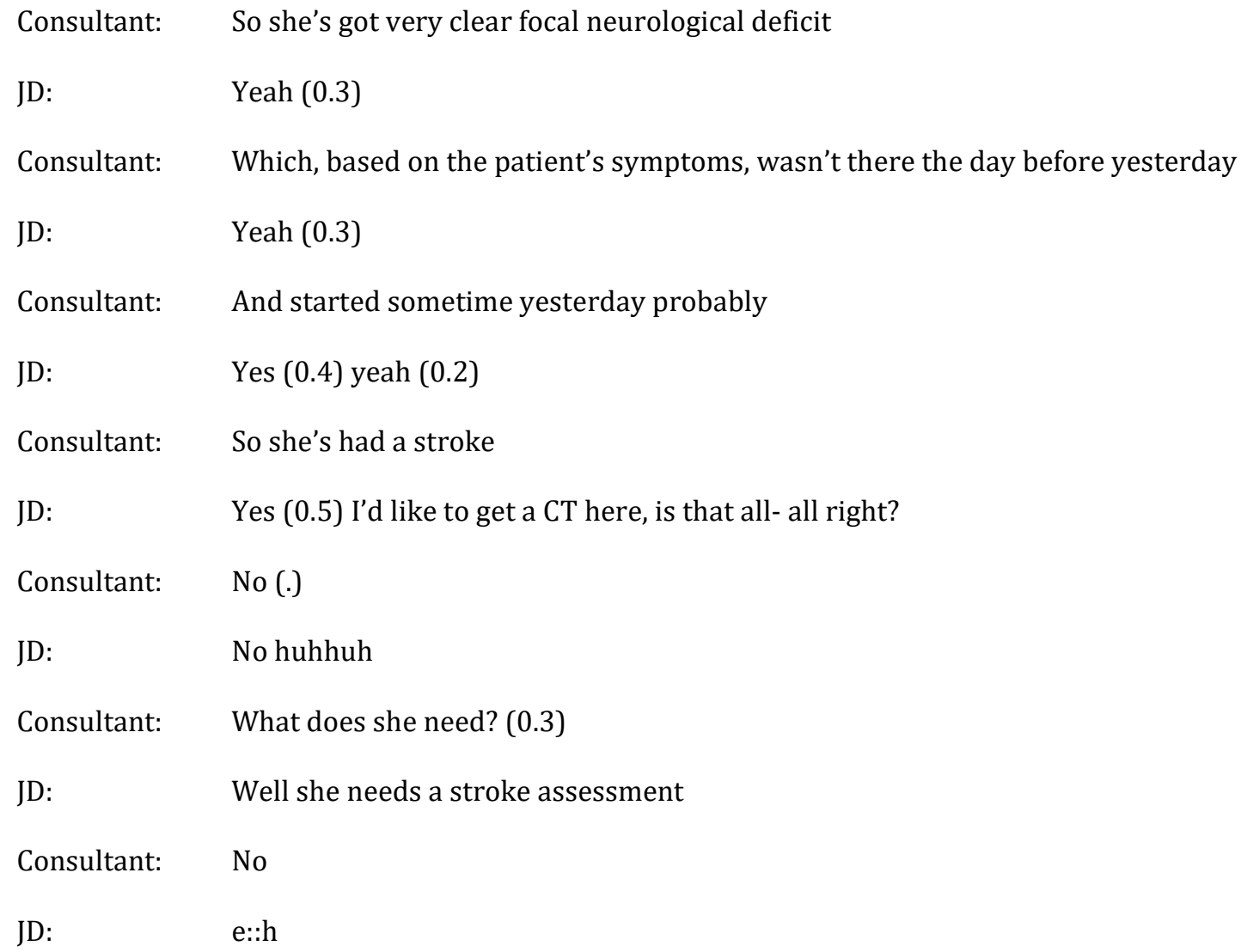




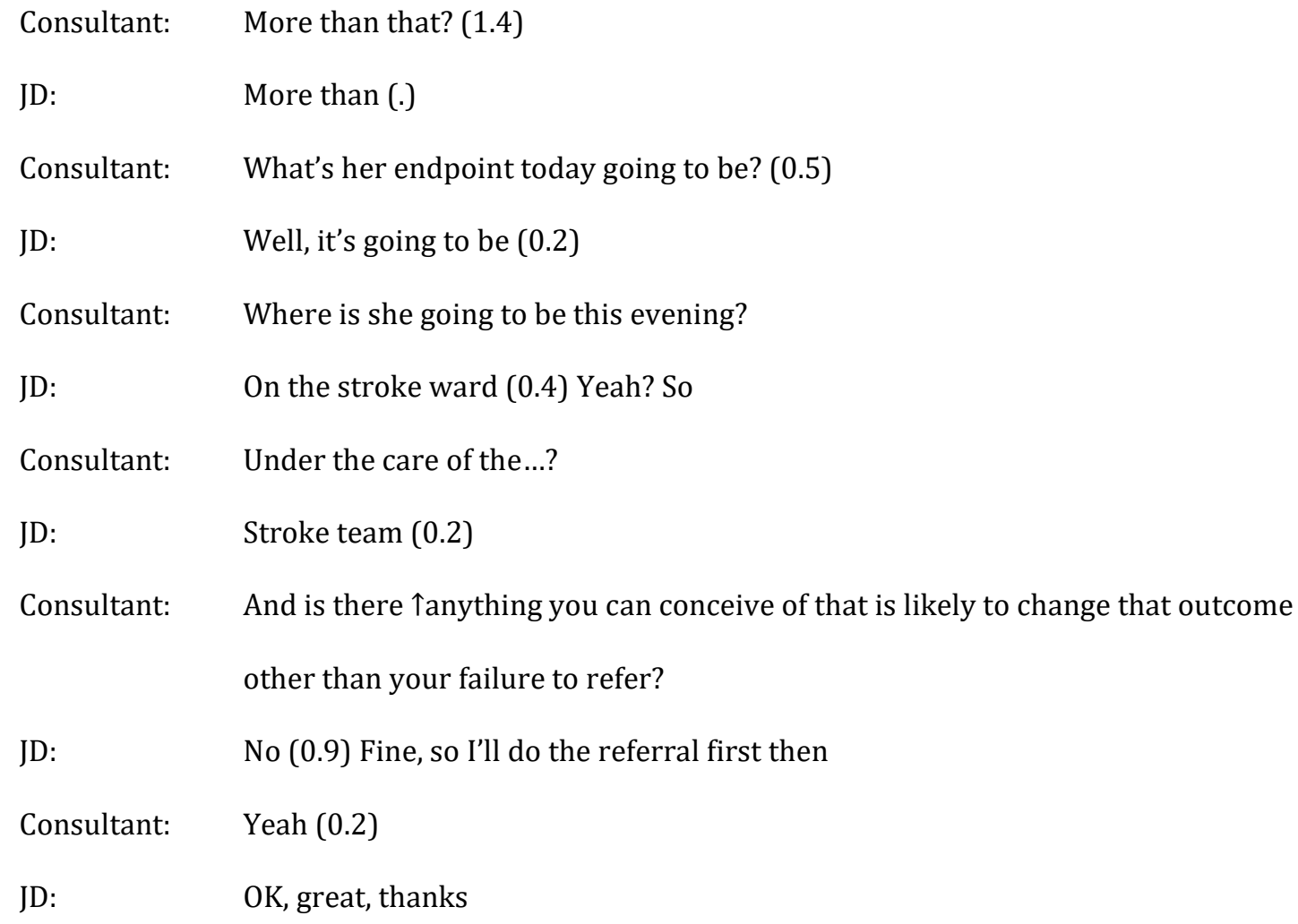

The consultant's initial 'so' highlights a transition, from questioning to summarizing. When the consultant states 'so she's had a stroke', he repeats the junior doctor's diagnosis, but the 'so', as well as the pauses after each confirmation, formulates this as his own conclusion. It also encodes a greater degree of certainty than the junior doctor's formulation, a move that establishes a division of expertise in which the consultant claims unmitigated modal superiority.

The consultant's 'no' - appearing twice - is unique in our data set: it is the only instance of a blunt rejection of a junior doctor's suggested investigative procedure. The subsequent turns manifest aspects of the IRE (initiate-responseevaluate) structure, characteristic of classroom and parent-child discourse. The consultant's questions limit and distribute the junior doctor's turns and are 
formulated as having known answers; the junior doctor has lost all rights, then, to initiate turns or negotiate meaning. The consultant asks questions until the required answer is provided: "the stroke team". The consultant's next turn is spoken with heavy sarcasm, and explicitly names the junior doctor's failure: "and is there anything you can conceive of that is likely to change that outcome other than your failure to refer?" The structure of this question leaves no doubt as to the expected answer, which the junior doctor dutifully provides.

The case illustrates the way in which pedagogic authority - by contrast to collegial reciprocity - can function to remind junior doctors of their place in the hierarchy and its obligations to superiors. The consultant's requests make apparent that it is not a lack of knowledge that caused the interactional disturbance: the diagnosis and its consequences are endorsed. What distinguishes this case presentation is the fashion in which it is offered. In starting with a diagnosis and then asking for an investigative procedure, the junior doctor does not offer gifts inviting an obliging return. His professional autonomy is then withdrawn, manifest in the IRE sequence. The consultant's reprimand has bureaucratic justification: a CT scan is not necessary, according to hospital protocols, to refer a patient to the stroke team. It is however conventionally expected; it is good etiquette. This may explain the subsequent interactional difficulties between the junior doctor and the stroke registrar, who does not accept the referral when the junior doctor states that this has been requested by the consultant (again, a unique example of this in our data set). The case closes - with respect to our data collection - only when the junior doctor tells the researcher that he will treat the stroke registrar's agreement to see the 
patient as a de facto referral. Breakdown in the circulation of gifts leads to breakdown in the distribution of responsibility.

\section{Conclusions}

We recruited Mauss' concept of the gift for two reasons. First, accounts of the case presentation which analyse it in terms of ventriloquizing, modelling and the appropriation of voice did not seem adequate for making sense of how junior doctors worked. Juniors are in training, but their training is what makes up clinical activity; it is not only a form of peripheral initiation, as is suggested by the use of Lave and Wenger's account of apprenticeship. Using Mauss' model of community, rather than Lave and Wenger's, thus changes how interactions between juniors and seniors can be interpreted.

Second, whilst the case presentation was often a dyadic encounter in our viewfinder, treating it as such analytically did not seem to do justice to its performative effects. It transformed a patient consultation into an account sustaining hierarchically-marked, collegial exchange. It re-distributed responsibility for a case, including to seniors who had no other involvement in it. It transformed investigations into a 'management plan'. It informed interactions with other departments in the hospital. In other words, it did a lot of work in making a case progress. Our use of Mauss highlights that it did not do this instrumentally; i.e. in terms of the accurate reporting of clinical information. Its ceremony manifested a normative order, which was not simply a reflection of either a cognitive or formal division of labour. 
This perspective has implications for understanding how collegiality is performed in A\&E, and also therefore, how novices might learn to act collegially. It suggests that the difficulties which junior doctors are perceived to experience with clinical decision-making - both in the pedagogically-oriented research literature as well in in our setting - may not effectively be addressed through an intervention aimed at them individually, in the tradition of the 'communications approach' (Strong, 2001). The problem does not appear to be a simple case of defective discursive competence or an inability to act autonomously. It relates to the creation and recognition of reciprocal obligations in the doing of collective work and the maintenance of an organized social environment.

Anspach RA. (1988) Notes on the sociology of medical discourse: the language of case presentation. Journal of Health and Social Behavior 29: 357-375.

Antaki C., Hotkoop-Steenstra, H., and Rapley, M. (2000) “Brilliant. Next question..." High-grade assessment sequences in the completion of interactional units. Research on language and social interaction 33(3): $235-262$.

Atkinson P. (1994) Rhetoric as skill in a medical setting. In: M. Bloor and P. Taraborrelli (eds) Qualitative studies in health and medicine. Aldershot: Avebury, pp.110-130.

Atkinson P. (1995) Medical talk and medical work: the liturgy of the clinic, London: Sage.

Atkinson P. (1999) Medical Discourse, evidentiality and the construction of professional responsibility. In: S. Sarangi and C. Roberts (eds) Talk, work 
and institutional order: discourse in medical, mediation and management. Berlin: Walter de Gruyter, pp.75-108.

Atkinson P. (2004) The discursive construction of competence and responsibility in medical collegial talk. Communication and medicine 1: 13-23.

Buchbinder M. (2017) Keeping out and getting in: reframing emergency department gatekeeping as structural competence. Sociology of Health and Illness 39(7). https://doi.org/10.1111/1467-9566.12566

Chan MY. (2015) The oral case presentation: toward a performance-based rhetorical model for teaching and learning. Medical Education Online, 20. http://dx.doi.org/10.3402/meo.v20.28565

Douglas M. (2002) Introduction. In: M. Mauss (ed) The gift: the form and reason for exchange in archaic societies. London: Routledge, pp.1-9.

Erickson F. (1999) Appropriation of voice and presentation of self as a fellow physician: aspects of a discourse of apprenticeship in medicine. In: S. Saranji and C. Roberts (eds) Talk, work and institutional order: discourse in medical, mediation and management settings. Berlin: Mouton de Gruyter, pp.109-143.

Fritsch M. (2015) The gift of nature in Mauss and Derrida. The Oxford Literary Review 37: 1-23.

Goodwin D. (2014) Decision-making and accountability: differences of distribution. Sociology of Health and Illness 36(1): 44-59.

Haber RJ. and Lingard LA. (2001) Learning Oral Presentation Skills: A Rhetorical Analysis with Pedagogical and Professional Implications. Journal of General Internal Medicine 16: 308-314. 
Hilligloss B. (2014) Selling patients and other metaphors: a discourse analysis of the interpretative frames that shape emergency department admission handoffs. Social Science and Medicine 102: 119-128.

Hillman A. (2013) 'Why must I wait?' The performance of legitimacy in a hospital emergency department. Sociology of Health and Illness 36(4): 485-499.

Hughes D. (1988) When nurse knows best: some aspects of nurse/doctor interaction in a casualty department. Sociology of Health \& Illness 10(1): $1-22$.

Hunter KM. (1991) Doctor's stories: the narrative structure of medical knowledge, New Jersey: Princeton University Press.

Karsenti B. (1994) Marcel Mauss: le fait social total, Paris: Presses Universitaires de France.

Kendrick KH. and Drew P. (2016) Recruitment: offers, requests, and the organization of assistance in interaction. Research on language and social interaction 49(1): 1-19.

Kennedy TJT., Regehr G., Baker GR., et al (2009) Preserving professional credibility: grounded theory study of medical trainees' requests for clinical support. BMJ 338: 399-401.

Konstantinou E and Fincham R. (2010) Not sharing but trading: Applying a Maussian exchange framework to knowledge management. Human Relations 64: 823-842.

Lave J and Wenger E. (1991) Situated learning: legitimate peripheral participation, Cambridge: Cambridge University Press. 
Lingard L., Garwood K., Schryer CF., et al (2003) A certain art of uncertainty: case presentation and the development of professional identity. Social Science \& Medicine 56: 603-616.

Lingard L., Schryer CF., Garwood K., et al (2003a) 'Talking the talk': school and workplace genre tension in clerkship case presentations. Medical Education 37: 612-620.

Lingard L. and Haber RJ. (1999) What do we mean by "relevance"? A clinical and rhetorical definition with implications for teaching and learning the casepresentation format. Academic Medicine 74: S124-127.

Mauss M. (1924) Essai sur le don: forme et raison de l'échange dans les sociétés archaïques, http://classiques.uqac.ca/classiques/mauss_marcel/socio_et_anthropo/2 _essai_sur_le_don/essai_sur_le_don.pdf

Nugus P., Bridges J. and Braithwaite J. (2009) Selling patients. BMJ 339: 14441446.

Pomerantz A. (2003) Modeling as a teaching strategy in clinical training: when does it work? In: P. Glenn, C. LeBaron and J. Mandelbaum (eds) Studies in Language and Social Interaction: In honor of Robert Hopper. Mahwah, NJ: Lawrence Erlbaum Associates, pp.381-391.

Pomerantz A., Ende J. and Erickson F. (1995) Precepting conversations in a general medicine clinic. In: GH. Morris and RJ. Chenail (eds) Talk of the clinic: explorations in the analysis of medical and therapeutic discourse. Mahwah, New Jersey: Lawrence Erlbaum, pp.151-169.

Saunders BF. (2008) CT Suite: the work of diagnosis in the age of non-invasive cutting, London: Duke University Press. 
Schryer CF. and Spoel P. (2005) Genre theory, healthcare discourse, and professional identity formation. Journal of Business and Technical Communication 19: 249-278.

Spafford MM., Schryer CF., Mian M. and Lingard L. (2006) Look who's talking: teaching and learning using the genre of medical case presentations. Journal of Business and Technical Communication 20: 121-158.

Stevenson F., Gibson W., Pelletier C., Chrysikou V. and Park S. (2015) Reconsidering 'ethics' and 'quality' in healthcare research: the case for an iterative ethical paradigm. BMC Health Services Research 16(21).

Stevenson F., Pelletier C., Gibson W., Park S. and Chrysikou V. (2019) The coconstruction of medical disposals in emergency medicine consultations. Social Science and Medicine. doi:10.1016/j.socscimed.2018.09.050

Strong PM. (1979/2001) The ceremonial order of the clinic: parents, doctors and medical bureaucracies. Aldershot: Ashgate.

Wallenburg I., Bont A., Heineman MJ., et al (2013) Learning to doctor: tinkering with visibility in residency training. Sociology of Health and Illness 35: 544-559.

Word count: 8006

Date: $23^{\text {rd }}$ October 2018 